Proceedings of the ASME $20134^{\text {th }}$ Micro/Nanoscale Heat \& Mass Transfer International Conference

MNHMT2013

December 11-14, 2013, Hong Kong, China

MNHMT2013-22105

\title{
LOCAL EXPERIMENTAL HEAT TRANSFER OF SINGLE-PHASE PULSATING FLOW IN A SQUARE MINI-CHANNEL
}

\author{
Balkrishna Mehta \\ Department of Mechanical Engineering \\ Indian Institute of Technology, Kanpur \\ Kanpur, UP, India
}

\author{
Sameer Khandekar \\ Department of Mechanical Engineering \\ Indian Institute of Technology, Kanpur \\ Kanpur, UP, India
}

\section{ABSTRACT}

Disturbing the flow with a particular pulsating frequency alters the thermal and hydrodynamic boundary layer thus affecting the inter-particle momentum and energy exchange. Due to this enhanced mixing, augmentation in the heat transfer is expected. Obviously, the parameters like pulsating frequency vis-à-vis viscous time scales and the imposed pulsating amplitude will play an important role in the enhancement of the heat transfer. Several numerical heat transfer and fluid flow studies on pulsating flows have been reported in the literature but the conclusions are not coherent. Lack of experimental study in hydrodynamics as well as in heat transfer of laminar pulsating flows attracts to revisit this problem especially, in mini-channels. Technological developments in measurement and instrumentation have enabled to experimentally investigate the thermo-hydrodynamic study of laminar pulsating flows in mini-channels as an augmentation technique for heat transfer. In this work, we have undertaken the experimental measurements of heat transfer of single-phase laminar pulsating flow in square mini-channel of cross-section $3 \mathrm{~mm} \times 3 \mathrm{~mm}$. The study is done at two different pulsating frequency $0.05 \mathrm{~Hz}$ and $1 \mathrm{~Hz}$ (Womersley number, $\mathrm{Wo}=0.8$ and 3.4 respectively). These two values are chosen because velocity profile exhibits different characteristic for Wo $>1$ (annular effect, i.e., peak velocity near the wall) and Wo $<1$ (conventional parabolic profile). The heat transfer study has been done in a square channel of made on polycarbonate sheet with one side heating. Heater (made of SS, 70 microns thin strip, negligible thermal inertia) itself is one of the walls of the square channel making constant heat flux thermal condition and its instantaneous temperature is measured by using pre-calibrated InfraRed camera. Fluid bulk mean temperature has been determined by energy balance and one K-type thermocouple is also placed in the fluid at the outlet cross-section. By using these temporal data, space averaged instantaneous Nusselt number has been obtained. It is observed that for measured frequency range, the overall enhancement in the heat transfer is not attractive for laminar pulsating flow in comparison to steady flow of same time-averaged flow Reynolds number. It is found that the change in species transport is either marginal or highly limited and is primarily occurring in the developing length of the channel/ plate. Enhancement of species transport due to such periodic pulsatile internal flows, over and above the nonpulsatile regular flow conditions, is questionable, and at best, rather limited.

\section{INTRODUCTION}

The fluid flow and heat transfer in pulsating flows are encountered in many engineering fields ranging from industrial application in heat exchangers, electronic cooling system, pulse tube dry cooling systems etc., to biological applications of arterial blood flow. The effect of pulsations on the heat transfer is an interesting problem to researchers due to its wide occurrences in many real time situations as mentioned earlier. The fluctuations are sometime inherent in the flow (flow over tube bundles where vortex shedding from the leading tube induces fluctuations for subsequent tubes) or it can be superimposed externally on the steady flow (Pulse jet cooling). Now-a-days cooling requirements are significantly increasing due to the miniaturization of the engineering devices. MEMS and Bio-fluidic systems are also gaining popularity.

Several researchers have been working towards finding the insight of the pulsatile flows from early decades of last century. In 1929, Richardson and Tyler [1] measured the velocity profile of the pulsating flow in tube of different cross sections and sizes and found the "annular effect". They observed that the maximum velocity occurs near the wall and not at the center of the pipe. Womersley [2] obtained the drag in pulsating pipe flow due to pressure gradient. In 1956, Uchida [3] obtained an 
analytical solution of the velocity profile for the pulsating flow in a tube and confirmed the "annular effect". In this solution, phase lag between velocity and pressure gradient was also observed and it was found that lag increases with frequency and asymptotically reaches to $90^{\circ}$ after a threshold frequency.

Siegel and Perlmutter [5] had shown the dependence of overall heat transfer on the frequency of pulsations. Furthermore, when constant temperature wall boundary condition was used, the Nusselt number showed periodic axial fluctuations. In other subsequent studies [6-11], hydrodynamic "annular effect", phase lag and periodic axial fluctuation of temperature and heat transfer were confirmed. But Seigel [12] argued that, for forced convection in slow laminar flow in a channel, oscillations reduced the heat transfer coefficient. Cho and Hyun [13], numerically investigated the effect of pulsation in a pipe using laminar boundary layer equations. They observed that at the fully developed downstream region, Nusselt number may increase or decrease depending on the frequency parameter. Kim et al. [14] studied the thermally developing but hydrodynamically fully developed channel flow and isothermal channel wall. They showed that flow pulsations hardly affected the thermal behavior. Guo and Sung [15] have observed that for small amplitudes, heat transfer gets augmented within a band of operating frequency but at higher amplitudes, heat transfer is always augmented. Hemida et al. [16] observed that pulsations produce little change in heat transfer, this being always negative. This small change is limited to the thermally developing region only. Yu et al. [17] and Chattopadhyay et al. [18] observed no change in time-averaged Nusselt number due to pulsations. Mehta and Khandekar [20] presented the numerical study of hydrodynamics and heat transfer of pulsating flows by applying sinusoidal velocity profile at the inlet and it was observed that pulsations hardly effect the heat transfer.

The above literature review does not converge to coherent conclusions. The results are not only sparse but inconsistent and sometimes contradictory. The key issue concerning heat transfer in pulsating internal convection is whether the superposed flow pulsations enhance heat transfer over the original steady flow. Unfortunately, the literature provides diverging answers, i.e (a) pulsations enhance heat transfer [19]; (b) it deteriorates the heat transfer [16]; (c) it does not affect the heat transfer $[5,17,18,20]$; (d) it either increases or deteriorates the heat transfer depending on imposed parameters $[14,15]$. The literature also lacks in experimental data. Thus, to clarify the present situation, systematic experimental studies are required.

We have therefore attempted to experimentally investigate heat transfer with flow pulsations of laminar thermally developing flow in a horizontal square mini-channel of cross-section $3 \mathrm{~mm}$ $\times 3 \mathrm{~mm}$ under constant heat flux condition as shown in Figure 1. Pulsating frequency values used in the experiments are 0.05 $\mathrm{Hz}$ and $1 \mathrm{~Hz}$ while amplitude ratio (A) is fixed at 0.6. Study is performed at fixed average Reynolds numbers of 170. The nondimensional frequency parameter are the Strouhal number (St) and Womersley number (Wo); the former only includes geometric and frequency parameter while the latter includes transport properties too.

\section{NOMENCLATURE}

A amplitude ratio (U/U $\left.\mathrm{U}_{\mathrm{av}}\right)(-)$

Bi Biot number $\left(h \cdot \mathrm{L}_{\mathrm{c}} / \mathrm{k}_{\mathrm{w}}\right)(-)$

D diameter $(\mathrm{m})$

$\mathrm{f}$ frequency of pulsation $(\mathrm{Hz})$

Fo Fourier number $\left(\alpha . t / \mathrm{L}_{\mathrm{c}}{ }^{2}\right)(-)$

$\mathrm{h}$ heat transfer coefficient $\left(\mathrm{W} / \mathrm{m}^{2}-\mathrm{K}\right)$

$\mathrm{k}$ thermal conductivity $(\mathrm{W} / \mathrm{m}-\mathrm{K})$

$\mathrm{L}$ length of domain in axial direction (m)

$\mathrm{Nu}$ Nusselt number $\left(\mathrm{h} . \mathrm{D}_{\mathrm{h}} / \mathrm{k}\right)$

Pr Prandtl number $(v / \alpha)$

q" heat flux $\left(\mathrm{W} / \mathrm{m}^{2}\right)$

$\mathrm{Re}$ average Reynolds number $\left(\mathrm{U}_{\mathrm{av}} . \mathrm{D}_{\mathrm{h}} / \mathrm{v}\right)$

St Strouhal number (f. $\left.D_{h} / U_{a v}\right)$

$\mathrm{t}$ time (s)

$\mathrm{T}$ temperature $(\mathrm{K})$

u axial velocity $(\mathrm{m} / \mathrm{s})$

Wo Womersley number $\left(\mathrm{d} .(\omega / \mathrm{v})^{0.5}\right)=(2 \pi \text {.St.Re })^{0.5}$

$\mathrm{z}$ axial length (m)

$\mathrm{Z}$ non-dimensional axial length (z/Re.Pr.D $\left.D_{\mathrm{h}}\right)(-)$

\section{GREEK SYMBOLS}

$\alpha$ thermal diffusivity $\left(\mathrm{m}^{2} / \mathrm{s}\right)$

$v$ kinematic viscosity $\left(\mathrm{m}^{2} / \mathrm{s}\right)$

$\omega$ angular frequency ( $\mathrm{rad} / \mathrm{s})$

$\theta \quad$ time period (s)

\section{SUBSCIPTS}

$\begin{array}{ll}\text { c } & \text { characteristic } \\ \text { f } & \text { fluid } \\ \text { h } & \text { hydraulic, hydrodynamic } \\ \text { in } & \text { inlet, instantaneous } \\ \text { r } & \text { relative } \\ \text { s } & \text { steady state } \\ \text { t } & \text { transient/ unsteady component } \\ \text { ta } & \text { time averaged } \\ \text { w } & \text { wall } \\ * & \text { dimensional quantity }\end{array}$

\section{EXPERIMENTAL DETAILS AND DATA REDUCTION}

The schematic and dimensional detail of experimental setup is shown in Figure 1. Constant temperature de-ionized and de-gassed water from thermal bath (Make: Julabo ${ }^{\circledR}$ F34 $\mathrm{ME}$, accuracy $\pm 0.1 \mathrm{~K}$ ) is supplied in the square mini-channel. An electronic L- series water flow meter (Make: ColeParmer $^{\mathbb{B}}$ ) is used to measure the transient flow rate. Time response of the flow meter is $20 \mathrm{~ms}$. Solenoid valves V1 and V2 (Make: Burkert ${ }^{\mathbb{R}}$ ) are used to provide the pulsation in the flow field. Solenoid valves are operated through electronic 


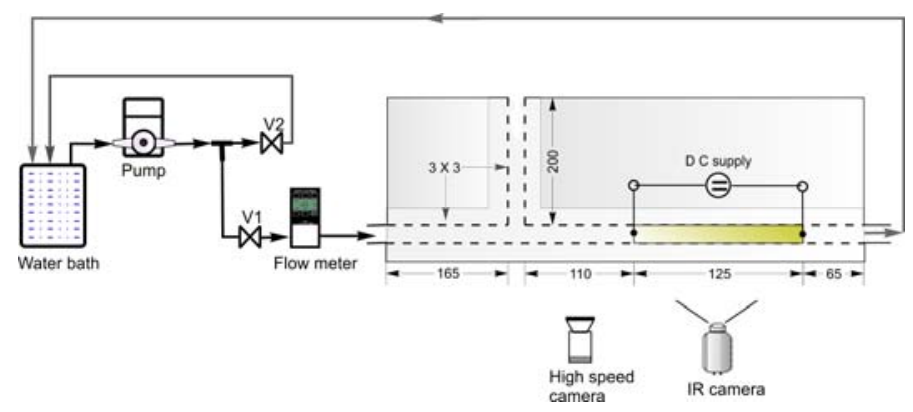

Figure 1 Schematic and dimensional details of experimental set-up

timer to achieve different frequency in the flow field. The pulsed flow generated by alternately opening the two valves, i.e, there will be a flow in the test section for half time period and no flow in the next half of the time period. Thus, the flow in the test section will result in square waveform. A precalibrated The IR camera used (Make: FLIR ${ }^{\circledR}$, Model: SC4000; Indium Antimonide detector array) has an operational spectral band of 3-5 $\mu \mathrm{m}, 14$ bit signal digitization and a Noise Equivalent Temperature Difference of less than $0.02 \mathrm{~K}$ at $30^{\circ} \mathrm{C}$ is used to measure the wall temperature. ThermaCAM ${ }^{\mathrm{TM}}$ Researcher V-2.9 is used to acquire the images from IR camera. Acquisition rate has been kept at $20 \mathrm{~Hz}$ and IR thermograms are captured at 320 pixels $\times 256$ pixels which give a spatial resolution of 330 microns in the axial z-direction and 375 microns in the transverse y-direction. NI-cDAQ 9172 with NI 9205 module and NI USB 9162 (Make: National Instruments ${ }^{\circledR}$ ) cards are used to acquire the voltage signal from flow meter and fluid thermocouple temperature located at outlet, respectively. These acquisitions are also done at $20 \mathrm{~Hz}$.

The time averaged Nusselt number is calculated as follows:

$\mathrm{Nu}_{\mathrm{ta}}=\frac{\mathrm{q}^{\prime \prime} \cdot \mathrm{D}_{\mathrm{h}}}{\left(\overline{\mathrm{T}}_{\mathrm{w}}-\overline{\mathrm{T}}_{\mathrm{b}}\right)_{\mathrm{ta}} \cdot \mathrm{k}_{\mathrm{f}}}$

$\overline{\mathrm{T}}_{\mathrm{w}}=$ local wall temperature at any given location along the $\mathrm{z}-$ axis, averaged along the direction of $y$-axis.

$\overline{\mathrm{T}}_{\mathrm{b}}=$ local bulk temperature determined by assuming linear variation from inlet temperature to outlet thermocouple temperature.

Non-dimensional temperature can be determined as:

$$
\mathrm{T}=\frac{\left(\mathrm{T}^{*}-\mathrm{T}_{\mathrm{f}, \text { inlet }}\right)}{\mathrm{q}^{\prime \prime} \cdot \mathrm{D}_{\mathrm{h}} / \mathrm{k}_{\mathrm{f}}}
$$

\section{RESULTS AND DISCUSSION}

In this section, effect of pulsation on the heat transfer is presented. The pulsations are generated by using solenoid valves hence the flow pattern in the channel follows the square waveform as shown in Figure 2. As the thickness of the heated wall is 70 microns, Biot number $\mathrm{Bi}=\mathrm{hL}_{\mathrm{c}} / \mathrm{k}_{\mathrm{w}}<<0.004$, i.e, there is no temperature gradient exist in transverse direction.
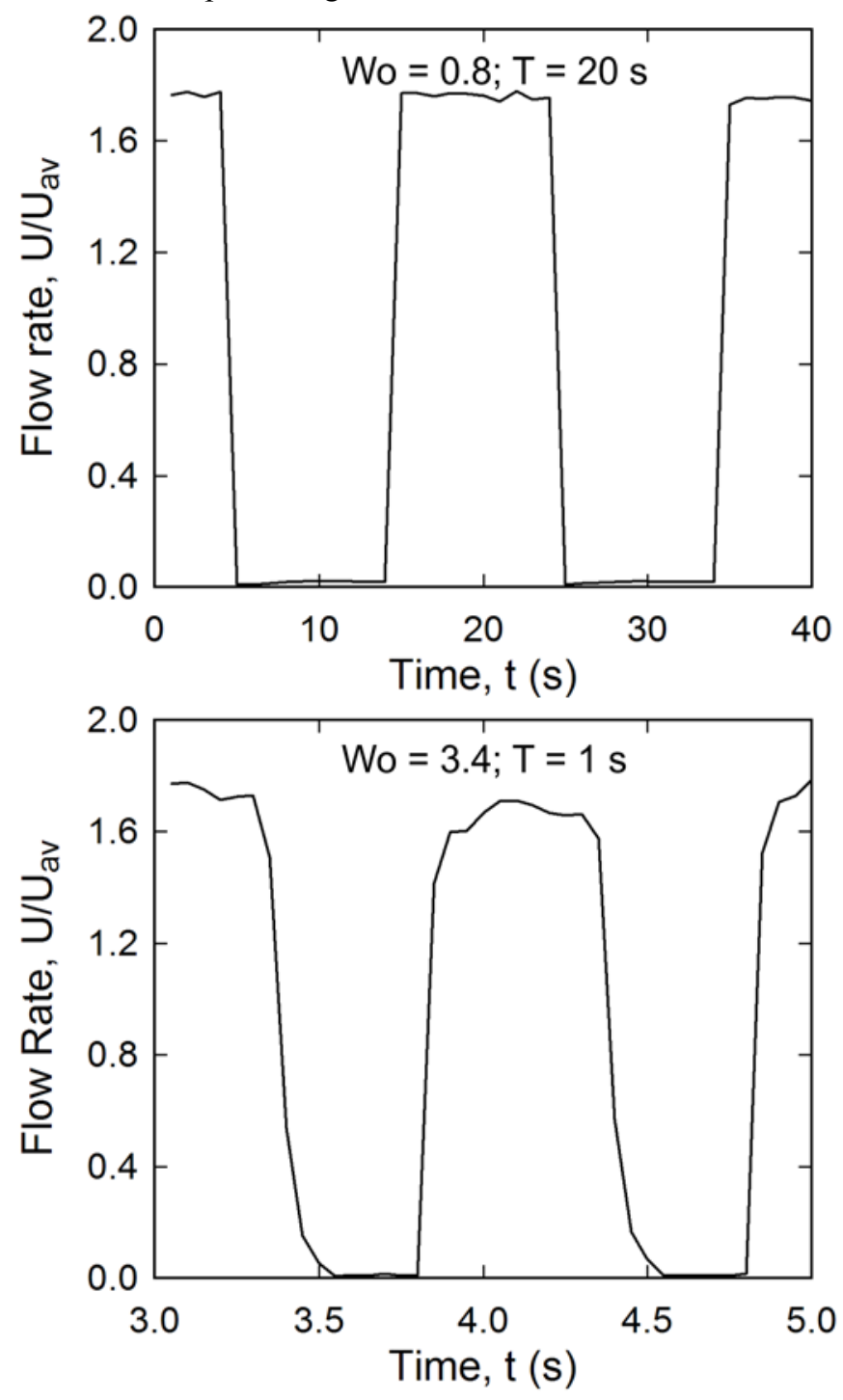

Figure 2 Imposed flow waveform for Wo $=0.8$ and 3.4

Table 1 Time scales for different frequencies

\begin{tabular}{|l|r|r|}
\hline Time scale (s) & Wo $=0.8$ & Wo $=3.4$ \\
\hline Diffusion in fluid, $\mathrm{D}^{2} / \alpha$ & 64 & 64 \\
\hline Time period, $1 / \mathrm{f}$ & 20 & 1 \\
\hline Convective time, $\mathrm{L}_{\mathrm{h}} / \mathrm{U}_{\mathrm{av}}$ & 1.875 & 1.875 \\
\hline Diffusion in solid, $\mathrm{L}_{\mathrm{c}}{ }^{2} / \alpha$ & 0.001 & 0.001 \\
\hline
\end{tabular}

Fourier number Fo $=\alpha . t / \mathrm{L}_{c}{ }^{2}$, for both the frequency values discussed here are 20000 and 1000 respectively. It means that imposed flow disturbance can be successfully captured in the thermal field. To validate this, frequency contained in the flow is revoked from the wall temperature acquired by IR Thermography and fluid thermocouple data. In Figure 3 and 4, 
FFT of the flow, wall and fluid temperature data has been shown
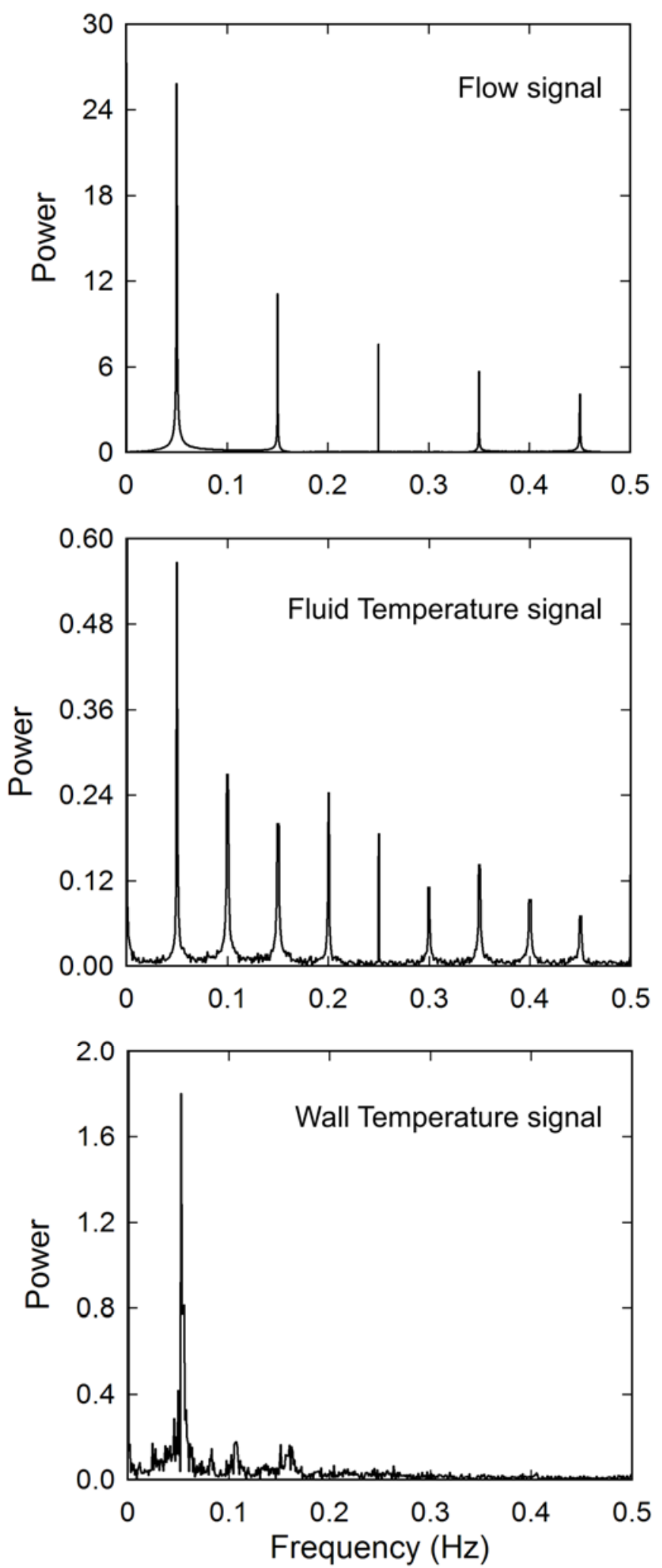

Figure 3 FFT plots for Wo $=0.8($ frequency $=0.05 \mathrm{~Hz}$ ) for both the frequency value. It is clearly observed that thermal inertia in the solid wall is negligible to die out the effect of flow.
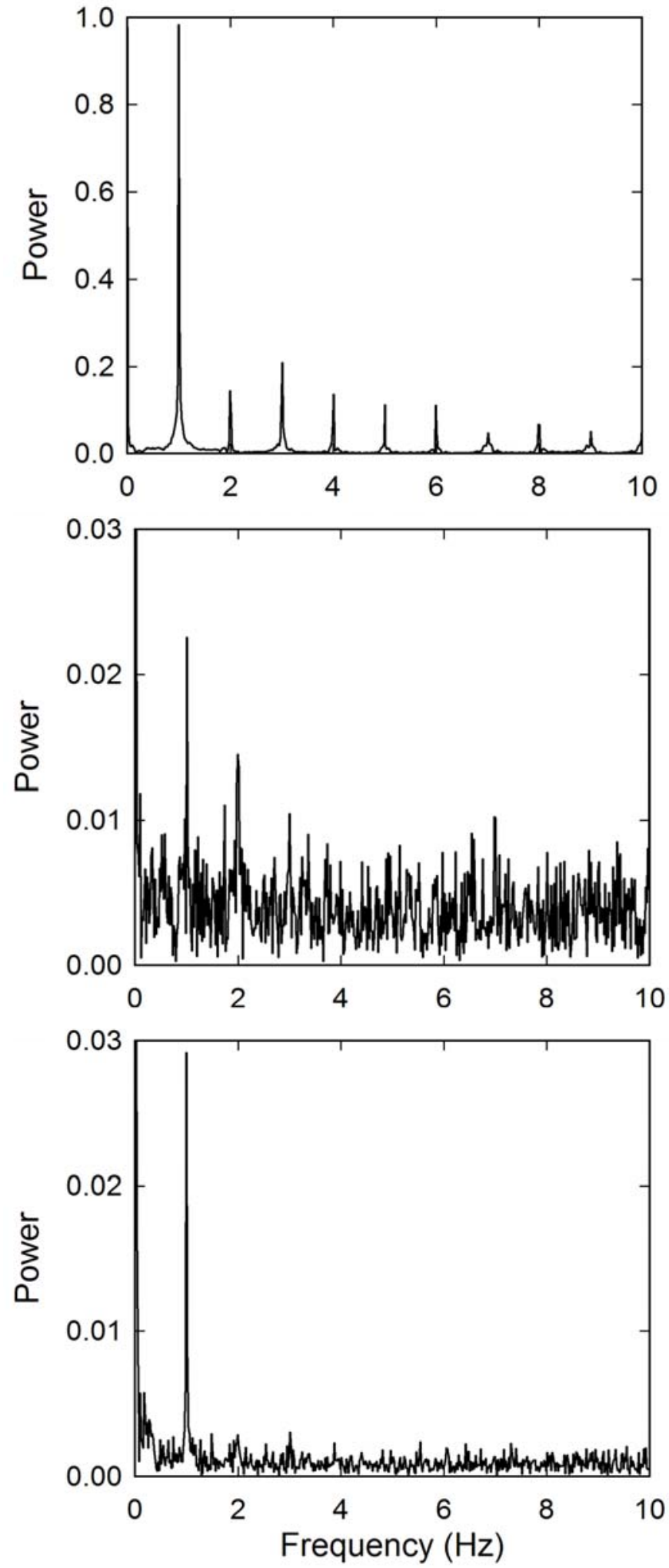

Figure 4 FFT plots for Wo $=3.4($ frequency $=1 \mathrm{~Hz})$ 
Due to transient nature of the flow, different time scales are involved which govern the thermal field pattern. These time scales are fluid diffusion time scale $\mathrm{D}^{2} / \alpha$, Time period $1 / \mathrm{f}$, Convective time scale $\mathrm{L}_{\mathrm{h}} / \mathrm{U}_{\mathrm{av}}$ and Solid diffusion time scale $\mathrm{L}_{\mathrm{c}}{ }^{2} / \alpha$. The values of these time scales are shown in Table 1 for $\mathrm{Wo}_{\mathrm{o}}=0.8$ and 3.4. Here, from Table 1 , it can be seen that for Wo $=0.8$ and 3.4 , diffusion in fluid and solid is quite fast i.e, whatever disturbances imposed in the flow field, is instantly diffused in throughout the solid and fluid domain. For Wo $=$ 3.4 , convective time scale is higher than the time period of imposed fluctuation i.e., heated zone is not completely renewed by fresh fluid particle in up phase while for $\mathrm{Wo}_{0}=0.8$, during up phase the fluid flow establishes fully in the heated zone. But
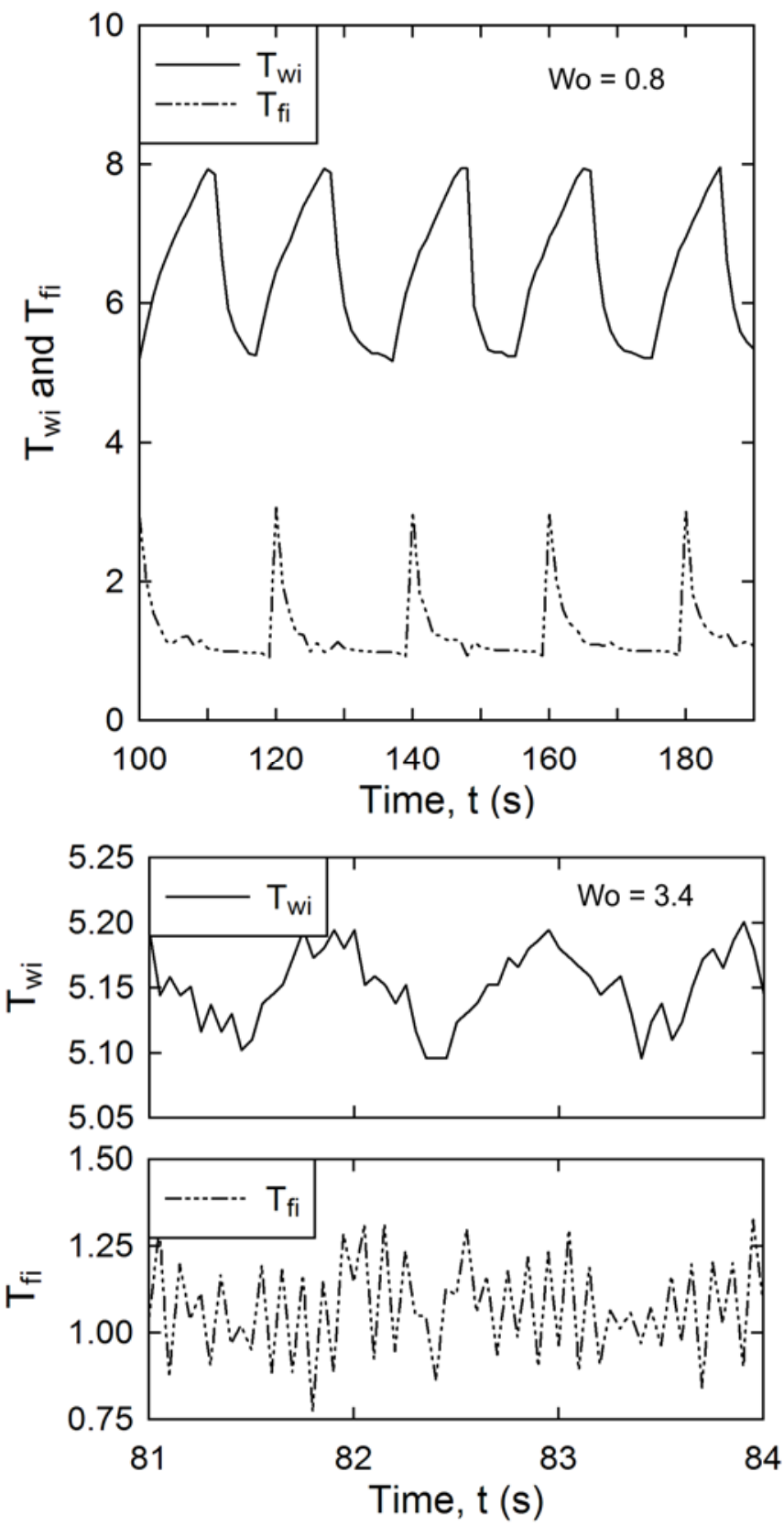

Figure 5 Instantaneous wall and fluid temperature for Wo 0.8 and 3.4
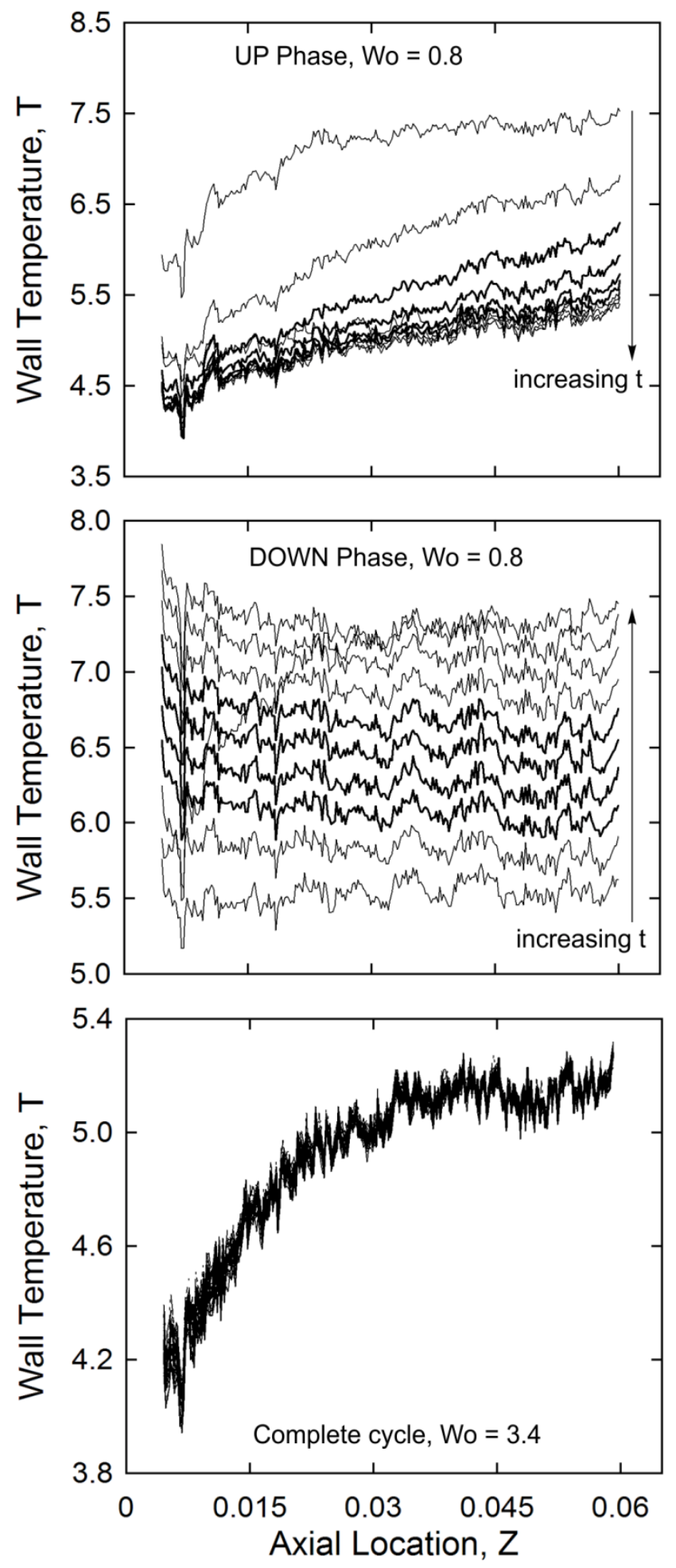

Figure 6 Wall temperature at various instants of a complete cycle for $\mathrm{Wo}=\mathbf{0 . 8}$ and 3.4

at the same time, in down phase the fluid stays in the heated zone for long period which will increase the wall temperature because heat is only transferred by diffusion. 
Figure 5 shows the instantaneous wall and fluid temperature at outlet for $\mathrm{Wo}=0.8$ and 3.4. It can be clearly seen that for $\mathrm{Wo}=$ 0.8 wall temperature is higher because of its higher residence time in the heated zone in the down phase. Figure 6 (a) and (b) shows the axial variation of wall temperature during up and down phase for Wo $=0.8$ respectively. It has been noticed that initially when flow starts during the up phase, axial temperature is very high and as flow progresses it quickly comes down.

The wall temperature profile is qualitatively similar as convective flow for constant heat flux condition. On the contrary, during the down phase wall temperature becomes approximately constant for throughout the channel length and it increase with the time. This is due to the diffusion in the stationary fluid in the heated zone. Figure 6 (c) shows the axial variation of wall temperature for Wo $=3.4$ for a complete cycle. Here, axial temperature distribution is qualitatively similar as internal convective flows. It does not exhibit the axially constant temperature pattern during the down phase
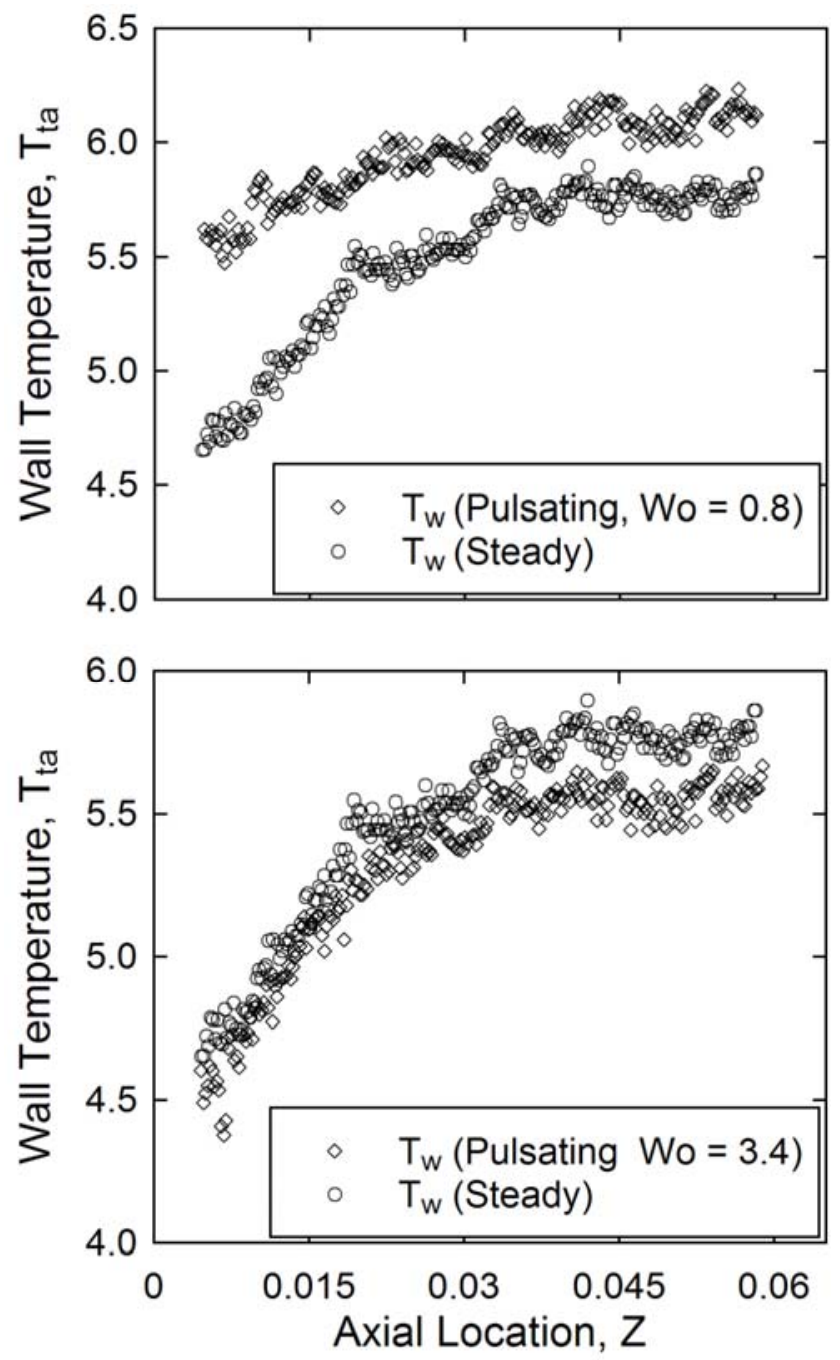

Figure 7 Comparison of axial variation of pulsating and steady state wall temperature for $W_{0}=0.8$ and 3.4 because of the comparable convective and diffusion time scales.

To get the overall picture of pulsation on wall and fluid temperature, axial distribution of time-averaged temperatures is plotted in the Figure 7 (a) and (b) for Wo $=0.8$ and 3.4 respectively. Figure 7 (a) shows the time averaged axial temperature profile of pulsating and steady flow for $\mathrm{Wo}=0.8$. It is observed here that wall temperature is higher in the case of pulsating flow than the steady flow. It is also interesting to note that pulsating flow axial temperature profile is moving towards constant temperature like the case, when heat is axially conducted in solid from high temperature to low temperature.

This is mainly due to the dominance of diffusion in the down phase which cannot be completely recovered by the convective up phase. In this case, the axial variation of the fluid temperature will not be linear. Unlike the previous case, for Wo $=3.4$, axial variation of time averaged wall temperature is similar as steady state temperature profile. It can be seen from Figure 7 (b) that pulsations hardly effect the heat transfer process.

Finally all the above analysis will be concluded by enhancement/deterioration of the time averaged Nusselt number due to application of pulsation over a steady flow. In Figure 8, axial variation of time averaged Nusselt number is shown for both the frequency. For comparison, corresponding steady state Nusselt number is also plotted.

As has been noted earlier that for Wo $=0.8$, the fluid temperature will be nonlinear, thus it cannot be evaluated by the energy balance as done in pure internal convective flow. But due to unavailability of any other method to find out the fluid bulk temperature, here, Nusselt number has been calculated by assuming linear variation. This will incorporate the large error quantitatively as well as qualitatively. Quantitatively, this assumption will over predict the time averaged Nusselt number for $\mathrm{Wo}_{0}=0.8$. But for $\mathrm{Wo}_{0}=3.4$,

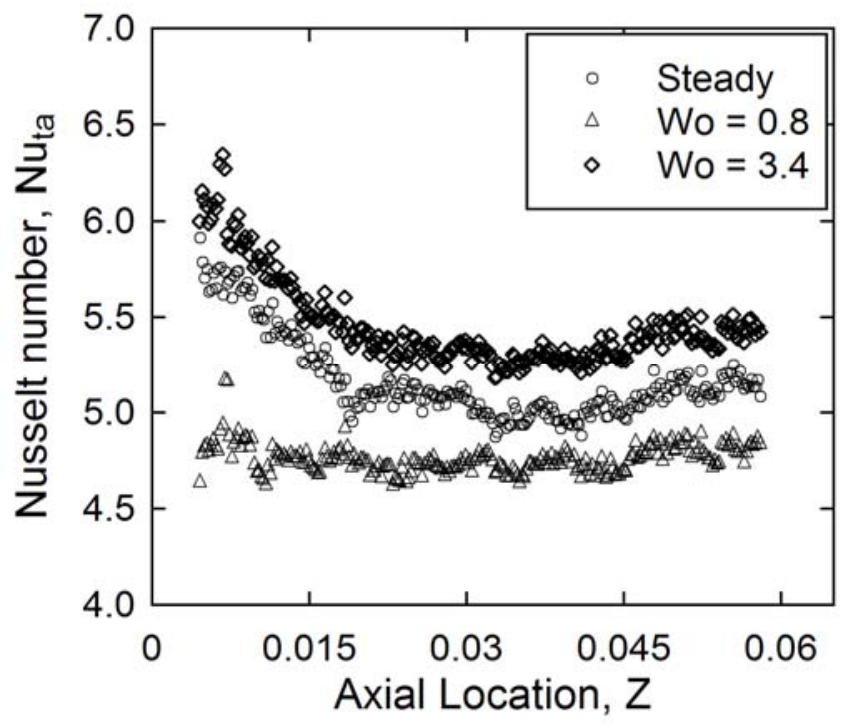

Figure 8 Axial variation of time averaged Nusselt number 
linear variation of the fluid temperature will be valid. In Figure 8 , it is observed that time averaged Nusselt number for Wo $=$ 0.8 is lower than the steady state value, as value is over predicted, in reality the heat transfer coefficient is smaller than what is shown here. On the other hand, for Wo $=3.4$, Nusselt number shows slight enhancement (at most $10 \%$ ) over steady state value. This marginal change in the Nusselt number is within the experimental uncertainty band i.e., it can be concluded that pulsations does not affect the heat transfer over steady state continuous flow.

\section{SUMMARY AND CONCLUSIONS}

In this paper effect of imposed pulsations on laminar thermally developing flow heat transfer in a square channel is studied. Frequency is the only variable, while amplitude and average Reynolds number are kept constant. It is found that, frequency does not have any significant effect on the heat transfer within the range tested in this present work. In fact, at very low frequency heat transfer is deteriorated.

\section{ACKNOWLEDGMENTS}

Financial grants for undertaking this research work, obtained from the Indo-French Center for Promotion of Advanced Research (IFCPAR), are gratefully acknowledged. InfraRed Thermography facility was developed by the grants received from Department of Science and Technology, Government of India.

\section{REFERENCES}

[1] Richardson, E. G., Tyler, E., 1929, "The Transverse Velocity Gradient Near the Mouths of Pipes in which An Alternating or Continuous Flow of Air is Established", The Proc. Of The Physical Society, 42 (231), pp. 1-15.

[2] Womersley, J. R., 1955, "Method for The Calculation of Velocity Rate of Flow and Viscous Drag in Arteries When The Pressure Gradient is Known", J. Physiol., 127, pp. 553563.

[3] Uchida, S., 1956, "The Pulsating Viscous Flow Superposed on the Steady Laminar Motion of Incompressible Fluid in a Circular Pipe", ZAMP, 7, pp. 403-422.

[4] Atabek, H. B., Chang, C. C., 1961, "Oscilattory Flow Near the Entry of a Circular Tube", ZAMP, 12, pp. 185-201.

[5] Siegel, R., Perlmutter, M., 1962, "Heat Transfer for Pulsating Laminar Duct Flow", ASME J. of Heat Transfer, (May), pp. 111-123.

[6] Phillips, E. M., Chiang, S. H., 1973, "Pulsatile Newtonian Friction Losses in a Rigid Tube", Int. J. Engg. Sci., 11, pp. 579-589.

[7] Muto, T., Nakane, K., 1980, "Unsteady Flow in Circular Tube", Bull. Of the JSME, 23 (186), pp. 1990-1996.

[8] Kita, Y., Hayashi, T., Hirose, K., 1982, "Heat Transfer in Pulsating Laminar Flow in a Pipe”, Bull. Of JSME, 25 (200), pp. 217-224.

[9] Creff, R., Batina, J., Andre, P., Karunanithi, V. S., 1983, "Numerical Model for Dynamic and Thermal Developments of a Pulsed Laminar Ducted Flow", Numerical Heat Transfer, 6, pp. 173-188.

[10] Creff, R., Andre, P., Batina, J., 1985, "Dynamic and Convective Results for a Developing Laminar Unsteady Flow", Int. J. for Numerical Methods in Fluids, 5, pp. 745-760.

[11] Al-Haddad, A. A., Al-Binally, N., 1989, "Prediction of Heat Transfer Coefficient in Pulsating Flow", Int. J. Heat and Fluid Flow, 10 (2), pp. 131-133.

[12] Siegel, R., 1987, "Influence of Oscillation-induced Diffusion on Heat Transfer in a Uniformely Heated Channel", Trans.ASME J. of Heat Transfer, 109, pp. 224-247.

[13] Cho, H, W., Hyun, J. M., 1990, "Numerical Solutions of Pulsating Flow and Heat Transfer Characteristics in a Pipe", Int. J. Heat and Fluid Flow, 11 (4), pp. 321-330.

[14] Kim, S. Y., Kang, B. H., Hyun, J. M., 1993, "Heat Transfer in the Thermally Developing Region of a Pulsating Channel Flow", Int. J. Heat Mass Transfer, 36 (17), pp. 42574266.

[15] Guo, Z., Sung, J. H., 1997, "Analysis of the Nusselt Number in Pulsating Pipe Flow", Int. J. Heat Mass Transfer, 40 (10), pp. 2486-2489.

[16] Hemida, H. N., Sabry, M. N., Abdel-Rahim, A., Mansour, H., 2002, "Theoretical Analysis of Heat Transfer in Laminar Pulsating Flow", Int. J. of Heat and Mass Transfer, 45, pp. 1767-1780.

[17] Yu, J., Li, Z., Zhao, T. S., 2004, “An Analytical Study of Pulsating Laminar Heat Convection in a Circular Tube with Constant Heat Flux", Int. J. of Heat and Mass Transfer, 47, pp. 5297-5301.

[18] Chattopadhyay, H., Durst, F., Ray, S., 2006, “Analysis of Heat Transfer in Simultaneously Developing Pulsating Laminar Flow in Pipe with Constant Wall Temperature", Int. Commn. in Heat and Mass Transfer, 33, pp. 475-481.

[19] Faghri, M., Javadani, K., 1979, "Heat Transfer with Laminar Pulsating Flow in a Pipe", Lett. Heat Mass Transfer, 6, pp. 259-270.

[20] Mehta, B., Khandekar, S., 2010, "Effect of Periodic Pulsations on Heat Transfer in Simultaneously Developing Laminar Flows: A Numerical Study", IHTC 14, Washington DC, USA, IHTC14-22519. 